\title{
THE FINNECIES OF MUSIC WED POETRY: \\ A MÚSICA E O FINNEGANS WAKE
}

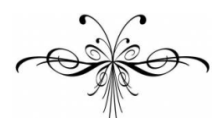

\section{CAETANO WALDRigues GALindo}

1.

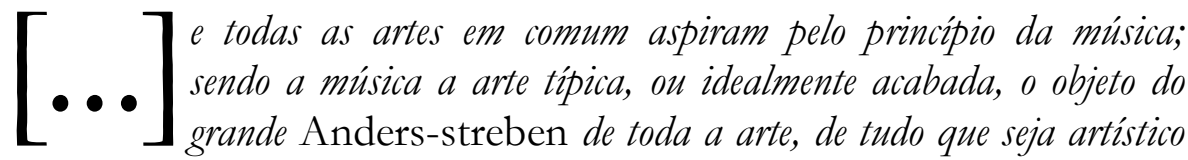
ou partilhe de qualidades artisticas.

Toda a arte constantemente aspira à condição da música. Pois enquanto nos outros tipos de arte é possivel distinguir o conteúdo da forma, e a compreensão sempre pode traçar essa distinção, no entanto é o esforço unânime de toda a arte obliterá-la. Que o mero conteúdo de um poema, por exemplo, ou seja, seu tema, aqueles incidentes e situações especificos - que o mero conteúdo de uma pintura, as circunstâncias efetivas de um evento, a topografia efetiva de uma paisagem - nada possam ser sem a forma, o espirito, do tratamento, que esta forma, este modo de tratamento, tornem-se um fim por si próprios, penetrem todo o conteúdo: e é em busca disso que a arte está o tempo todo, e é isso que ela atinge em graus variados. ${ }^{1}$

As duas ideias centrais deste famoso trecho de Walter Pater são a união forma-conteúdo e, claro, aquele Anders-streben, que definiria todo o trabalho artístico.

O conceito, emprestado por Pater da crítica alemã, representa na essência este mesmo movimento, este ansiar-pelo-outro, que faria com que as artes conseguissem superar parcialmente suas limitações específicas, buscando materiais, fontes e aspirações umas nas outras, fazendo com que a escultura, por exemplo, anseie pela cor e a reproduza ou subsuma com seus meios, assim como a pintura o faria com a tridimensionalidade. Tudo em busca de uma espécie de über-kunst, ou, talvez mais especificamente, de um über-künstlerisch, um ultra-artístico que definisse de vez o espírito não das artes mas da Arte.

Tudo isso, também, em um processo portanto de constante, necessária e incontornável tradução ${ }^{2}$. Em que tanto o contato efetivo de

\footnotetext{
${ }^{1}$ Walter Pater: The Renaissance, Studies in Art and Poetry, p. 115 (tradução minha)

${ }^{2}$ E não me preocupo aqui demasiadamente com ideias específicas de "tradução intersemiótica", por exemplo, mas com a ideia mais geral, e quase diria intuitiva, do processo relacional de
} 
um gênero com o outro, de uma arte com a outra, quanto a potencialidade, prenhe e premente, desse contato geram um transporte constante entre fronteiras aparentemente estanques.

Ao localizar precisamente na música o objetivo dessa cruzada, ao chamar a música de arte consumada, definitiva (embora não privada daquela ânsia pelo outro, como ele mesmo demonstra poucas páginas antes, em uma discussão sobre música figurativa), Pater a coloca em um lugar privilegiado que outros, antes e depois dele, também lhe atribuíram. Outro de toda a arte, de todas as artes, a música, por fim, é A arte, a forma final de toda uma estética que, em outras formas de tratamento, aparece sempre incompleta, sempre ansiando por se libertar de suas próprias amarras, sem jamais fazê-lo de fato. A música seria a meta de todo o processo de transporte, efetivo ou projetado.

No que se refere à literatura, e especialmente à poesia, essa aproximação pareceu sempre mais agônica, talvez precisamente porque tenha podido parecer mais realizável em diversos momentos. Mais tantalizantemente próxima de uma conclusão, de uma realização final.

Descontado o fato de que a poesia efetivamente parece ter surgido da e com a música, de que as origens de ambas as formas de manifestação se perdem juntas e, quando encontradas, inúmeras vezes juntas ressurgem; descontado o fato de que é ainda defensável a ideia de que a mesma linguagem tenha surgido com a música, se não da música, a aproximação realizada em diversos momentos, contextos e formatos se transformou em forma de convívio simbiótico. Criamos diversas formas de arte que se baseiam não no Anders-streben da poesia em relação à música, mas num aparente convívio das duas formas. A lírica clássica, a ópera, o lied, a canção popular. Formas em que a tradução antes mencionada, além de potencial e definição, existe como constatação de opostos. Formas artísticas bilíngües.

Nelas a poesia não aspira à condição de música, pode-se argumentar; elas efetivamente se fundiram em um todo indissolúvel ou, ao menos, analisável de forma mais profícua como uno e inconsútil.

Contudo, o que se vê em qualquer dessas formas é simplesmente convívio, realizado de maneiras as mais inventivas e produtivas, mas sem ultrapassar realmente os limites do outro. Posso, ainda que crua e "cruel"mente separar de um o outro, olhar para a poesia e a música no que tenham de específico seu e inalienável. Posso, nesse processo, quando se trate de uma ária, de uma canção especialmente bem realizada, chegar à freqüente conclusão de que se perde nele boa parte do mérito de uma e de outra. De que, portanto, ambas se completavam como canção precisamente

transposição, de transporte efetivo, que faz com que do ponto de vista de quem trabalha com a tradutologia, o Anders-Streben de Pater seja melhor definido por esse campo e esse processo do que por qualquer outro exemplo. 
no que reconheciam de falta e no que da outra tomavam como presença de um outro.

Mas não há morte da forma restante. A cisão é possível. Há entrelaçamento, sim, mas ele talvez apenas realce aquele Anders-streben em cada uma das artes envolvidas. esfera.

A busca de que falava Pater pertencia definitivamente a outra

Que foi normalmente objetivada pelos poetas.

Se Verlaine sintetizou ${ }^{3}$ talvez essa postura em seu de la musique avant toute chose, mal pagaria a pena recolhermos aqui citações de poetas que, em variados momentos e contextos, do renascimento italiano ao concretismo brasileiro, manifestaram com e em todas as letras seu desejo de transcender todas as letras e fonemas e não apenas aspirar à condição de música, mas realizar algo que mais lhes parecia descritível como a realização de um potencial plena e paterianamente presente na própria forma de arte que praticavam.

O poema não parece buscar na música a mesma coisa que a escultura quer da pintura, a colmatação de uma lacuna, a superação de uma limitação. A essas poéticas o poema parece de fato pretender ser música em germe, e declarar-se pleno enquanto poema apenas em sua realização como música.

O Lance de Dados, de Mallarmé, talvez tenha sido precisamente o momento em que a poesia foi mais longe nessa tentativa de integração, de fusão final com a música, indo muito além do mero tratamento formal da superfície verbal (ritmo, efeitos sonoros "musicais" como a assonância, as rimas, aliterações) e entrando em uma área em que a música era concebida não como verniz, como camada posterior de embelezamento beletrístico, afinal, mas como arte em sua totalidade, muito distante da poesia e, portanto, geradora de uma aproximação que, realizada, terá muito de muito mais violento que o mais "musical" dos poemas de Verlaine, precisamente por deixar de considerar o "musical" como um ornamento do poético, por fazer com que as duas coisas coincidissem, e talvez colidissem, em um projeto único, anterior, que aboliria essas hierarquias e subdeterminações.

Quando Mallarmé escreve a seu amigo Cazalis em 1864, dizendo

Invento uma língua que deve necessariamente brotar de uma poética muito nova, que eu poderia definir nestas duas palavras: Pintar, não a coisa, mas o efeito que ela produr.

a curiosa, curiosamente, referência ao ato de pintar, em alguém tão consciente das palavras como Mallarmé, mesmo em sua mais "prosaica"

\footnotetext{
${ }^{3}$ No poema "Art Poétique".
} 
correspondência ${ }^{4}$, atesta já precisamente aquela ânsia totalizante, que, Pater já sabia, aponta apenas para a música como solução. E, ainda, se Mallarmé não quer descrever as coisas, quer pintá-las, se sequer são as coisas que pretende pintar, mas sim e apenas os efeitos por elas produzidos, é apenas à música que pode correr, imaterial, puro efeito sobre o espectador, puramente desprendida do mundo das coisas. Ele quer não se enfeitar de música, mas sê-la, em letras.

2.

Mallarmé talvez estivesse se dedicando a uma fusão final, a uma superliteratura definitiva, no projeto a que se referia como Le Livre, destruído por ordem sua quando de sua morte. Jamais saberemos. Assim, o Lance de Dados resta como o mais claro testemunho daquele processo. Outro autor, outro texto, no entanto, terão realizado de forma ainda mais completa aquele projeto, ainda que de maneira algo diferente. E é da possibilidade da fusão das condições da literatura e da música no Finnegans Wake, de James Joyce, que trato daqui para frente.

E o projeto de Joyce no $W$ ake era ainda outro, mais estranho, ainda mais extensivo.

Diferente mesmo do que o próprio Joyce, leitor e admirador de Verlaine, poderia ter declarado anos antes, quando aceitou a descrição de seu poema 'Simples', como "pura música"5. Diferente ainda do que intentaria no Ulysses, especialmente no episódio conhecido como As Sereias, todo ele escrito com base em referências a música, a termos musicais, a técnicas musicais e, mais ainda, estruturado frouxamente sobre o modelo de um cânon. Nesses dois casos, afinal, ainda estamos (por mais que o segundo demonstre pretensões mais violentas) no mundo em que a música fornece arcabouços, polimentos, recursos que enobrecem, enfeitam a literatura.

O lado mais radical das Sereias se deve, claro, ao uso de um mecanismo estruturador efetivamente musical, quase antiliterário, o que fica mais do que óbvio na "abertura" do episódio, em que todo o sentido se perde numa recolha de trechos que ainda voltarão a aparecer, aí então devidamente contextualizados, apresentados aqui em sua futura ordem de surgimento, mas selecionados basicamente por seu caráter sonoro, musical, numa técnica que mais se próxima da abertura operática do que da efetiva apresentação de um sujeito de fuga, mas que de qualquer maneira deve à música, mais que uma estrutura externa, o desdém pelo sentido, pela

\footnotetext{
${ }^{4}$ Devo essa e todas as informações sobre Mallarmé e sobre a poesia francesa (assim como quase tudo que sei sobre artes plásticas) à professora Sandra M. Stroparo, que para minha sorte vive comigo.

${ }^{5}$ Richard Ellmann. James Joyce, p. 382.
} 
pintura da coisa, segundo Mallarmé. Trata-se de um trecho que, em uma primeira leitura, representa apenas ruído, com mínimos traços de uma semântica, uma narrativa reconhecível.

O James Joyce que buscaria correspondências sensórias para o ouvido absoluto musical, no entanto, era ainda mais próximo da cruzada de Mallarmé e de Pater ${ }^{6}$. E estava definitivamente mais próximo do Joyce que, poucos anos depois, escreveria o Finnegans $W$ ake e, dentro dele, o trecho conhecido como Anna Livia Plurabelle, descrito pelo próprio autor como música (seu capítulo mais "melódico"7), ao mesmo tempo em que reconhecia que, Ou o fim da Parte I [Anna Livia Plurabelle] é alguma coisa ou en sou um imbecil em meu julgamento de linguagem ${ }^{8}$.

Mas, para realizar essa aproximação efetiva, essa tentativa radical de saltar a lacuna entre as duas formas e (reconhecendo perfeitamente a hierarquia mais ampla delineada por Pater) finalmente dissolver em música a literatura, Joyce teve de dar conta de alguns elementos fundamentais da relação entre as duas artes, alguns elementos que costumam ficar de fora da maioria dos discursos que atribuem qualidades "musicais" a este ou àquele poema ou, da mesma maneira, emprestam atributos "discursivos" a uma ou outra peça de música absoluta.

Pois se o fato de as duas formas artísticas em questão se realizarem na linha do tempo faz efetivamente com que a aproximação entre elas seja mais direta do que a que se poderia encontrar entre a literatura e as artes plásticas, por exemplo, outros elementos, centrais a cada uma delas, as distanciam de maneira ainda mais vigorosa.

Pois se ambas gozam de uma grande similaridade fruitiva, se a experiência de se ler um livro é mais semelhante à de se ouvir um poema sinfônico na medida em que ambas dependem de um suceder de momentos ordenados, que não poderiam ser alterados sem alteração de efeito, ao passo que um quadro, uma escultura, são obras de entrada livre, de aproximação individual, cuja fruição se realiza em ordens e de maneiras diferenciadas, ainda é claro que aquela fruição, contudo, se baseia em elementos antagônicos e, talvez, irreconciliáveis. Fico aqui com três deles.

\section{a. Semântica.}

A possibilidade de "dizer" coisas, por mais banal, por mais óbvia que possa parecer, é sempre um elemento negligenciado nas pretensas aproximações poesia-música.

Quando Mallarmé declara pretender pintar efeitos, quando qualquer poeta, mesmo o Joyce dos anos 1910, declara pretender que seu

\footnotetext{
${ }^{6}$ Idem, p.439.

${ }^{7}$ Idem, p. 602.

${ }^{8}$ Idem, p. 589.
} 
poema seja música, apenas música, música antes de tudo, ele normalmente oblitera o fato de que atingir esse objetivo seria alcançar através da linguagem a total desfiguração da linguagem, sua negação, retirar da linguagem o que de mais típico ela possa ter. A música, afinal, a efetiva pintora de efeitos, não diz coisa alguma. E é essa sua força.

Posso sentir qualquer gama de efeitos, posso acreditar que uma determinada peça comunique isto ou aquilo, mas jamais poderei comprovar ou argumentar, sintática e semanticamente, contra as "ideias" declaradas, digamos, por um prelúdio barroco, com a opinião sobre qualquer ponto do mundo que sustenta os argumentos das variações Goldberg.

A tensão entre o "o quê" se diz e o "como", a matéria sonora e, por isso mesmo, musical, do poema, foi sempre um dos elementos definidores de posturas e atitudes em poesia. O mesmo Mallarmé, afinal, declarara que não é com ideias que fazemos poemas, mas com palavras ${ }^{9}$. No entanto, buscar a efetiva musicalidade, o efetivo domínio pleno da materialidade fônica sobre a semântica, implicaria produzir apenas música, abrindo mão do elemento lingüístico, literário, poético.

Desprover, de uma maneira qualquer, de ideias as palavras para poder lidar apenas com elas (letras, sons) geraria não uma poesia mais musical, mas uma poesia-apenas-música, ou, no máximo, uma poesiaapenas-gráfica, quando no papel. Qualquer possibilidade de ancoragem desta arte, gráfica ou fônica, no domínio da, ainda, poesia depende de uma ancoragem sua no domínio da linguagem e, por sua vez, da semântica, ainda que vestigial.

Daí, dessa ancoragem progressivamente mais tênue, a necessária dificuldade, obscuridade, do Lance de Dados, bem como de qualquer outra poesia que tenha levado mais adiante a constatação de Pater.

Uma glosa de um poema de Verlaine (discurso citado, tradução, ambas constatações da existência de um conteúdo semântico prévio) é infinitamente mais fácil que a glosa do Lance de Dados, por sua vez ainda bem mais direta que qualquer glosa de qualquer trecho do Finnegans $W$ ake. E todas elas serão imensuravelmente mais simples que uma glosa discursiva das Baricades Silencieuses de Couperin. Mas em breve chegamos a isso.

O compositor americano Aaron Copland definiu a questão de maneira mais específica quando declarou

O problema todo pode ser declarado de maneira muito simples atraves das perguntas: "A música tem um significado?" Minha resposta seria "Sim". E "Você pode dizer em palavras claras qual é este signifcado?" Minha resposta neste caso seria "Não".

E na ausência de uma estrutura semântico-sintático-discursiva, abre-se para a música todo um outro universo estrutural e organizacional

\footnotetext{
${ }^{9}$ Em comentário citado em "Psychologie de l'Art", de Henri Delacroix.
} 
baseado em efetivos "valores puros", efetivas estruturas que se tornam outro objeto de cobiça para os poetas. Que de novo podem assim simplesmente desconsiderar o fato de que a organicidade das mais simples estruturas musicais só é possível pelo fato de elas não serem linguagem, de negarem elementos centrais da linguagem, elemento estruturador externo, portanto.

O mais estruturado dos sonetos, afinal, ainda terá uma organização menos necessária que a de um mero acorde diminuto, digamos.

É mesmo interessante pensar, tendo em vista o peso do argumento da fusão forma-conteúdo para suas afirmações sobre a primazia da música sobre as demais artes, a que resultado teriam chegado as indagações de Pater tivesse ele tido acesso, digamos, a Pollock, a Rothko. A total abolição do "tema" como entidade separada faz com que em sua arte o "O que se diz" deixe de existir, gerando, como em termos musicais, uma arte que é apenas forma, nenhuma tensão, um caminho inacessível para a poesia, que, assim, de arte privilegiada na relação com a música, passa a pólo de maior angústia e impossibilidade de solução.

De outro lado, a radical atemporalidade da "tela" continua sendo um distanciador total, fazendo com que no máximo tal pintura se assemelhe a fatias de música, a momentos musicais, restando na busca pelo ritmo, pelo fluxo, pelo desenvolvimento, o ágon das artes plásticas em direção da música, presente desde a Perséfone de Bernini, por exemplo, até às composições de Mondrian.

\section{b. Simultaneidade.}

Outro ponto de cisão, devidamente escamoteado sobre a similaridade do desenvolvimento na linha do tempo, é a necessária monodicidade de linguagem, e consequentemente poesia. Nela as coisas se sucedem, uma de cada vez, linear, irreversível e singularmente. normalmente.

A música, claro, também pode sê-lo. Mas pode mais. E

A mera ideia de um acorde, da execução simultânea, de três, quatro, onze notas gerando um todo em que cada parcela é simultaneamente ativa, presente, detectável, singularizável e, de outro lado, imersa, parte, contribuinte, é por definição alheia aos princípios da linguagem. Com a exceção de dados marginais, supra-segmentais, ela continua linear, singular.

Um poema, assim, mesmo o mais "musical" dos poemas líricos, pode quando muito se aproximar de uma melodia. E melodias são apenas "partes" do ferramental musical. E, num certo sentido, a parte mais superficial. 
$\mathrm{E}$ isso, claro, não pôde passar despercebido aos poetas que se interessaram por essa aproximação. Era esse um dos objetivos, afinal, da poesia concreta que, em sua manifestação de-papel no entanto, conseguiu muito mais se aproximar das artes gráficas, em poemas que, abolindo a apresentação linear consecutiva, passavam a permitir (pelo mesmo processo que tentava negar aquela linearidade) uma fruição diferente, aberta, atemporal, que na verdade os afasta da música.

Foi na poesia vocalizada, gravada, que as aproximações mais interessantes puderam se dar. Foi aqui que a simultaneidade pôde se impor.

Mas pense por um momento no que eram realmente os poèmes simultanés dos dadaístas fundadores. Neles, multilinguismo e nonsense (guarde as duas noções), acabavam por manifestar uma espécie de despręo pela discursividade, pela semântica, afinal, nada estranho ao movimento como um todo. Esses poemas, sim, se aproximavam marcadamente do universo musical, mas à custa de uma perda, levianamente enfrentada, que Mallarmé provavelmente não teria ousado encarar.

De outro lado, obras mais recentes como The Idea of North, de Glenn Gould, construída a partir da colagem de diversos fragmentos de entrevistas, que se sobrepõem em padrões determinados apenas por critérios estéticos-musicais, encontram uma nova maneira de fazer o sentido submergir no fônico. Gould, afinal, era pianista. Ele estava se apropriando da linguagem como material sonoro, tangendo naquele momento os ideais da música concreta e de boa parte da vanguarda do pós-guerra, sintetizados na frase atribuída a Luciano Berio, de que música é tudo que se ouve com a intenção de ouvir música.

É de novo a música, afinal, afirmando aquela superioridade pateriana, e dissolvendo em seu meio o que lhe aprouver. É no entanto difícil de argumentar em favor da poeticidade da obra de Gould, que em outros momentos, no entanto, soube muito bem usar os modelos da canção, do madrigal, mais especificamente, e mesmo da fuga vocal.

\section{ab. O Wake.}

Antes de entrar no terceiro ponto, pode ser mais adequado expor como o Finnegans $W$ ake encara estes dois primeiros problemas, porque a resposta para as duas coisas se baseia em um mesmo fato: o trocadilho multilíngüe.

Joyce, no Wake, não nega a semântica. Não abre mão do significado (embora se apóie vigorosamente na possibilidade de que extensos trechos do romance sejam compreendidos mais afetivamente, quando não compreendidos de todo, apenas por uma leitura em voz alta), 
mas relativiza-a de forma extrema, como qualquer leitor de primeira viagem terá percebido.

Ele é, sim, capaz de usar apenas "palavras", como prescrevia Mallarmé, mesmo a contra-pêlo de seus significados distintos e combinados, como no famoso trecho que pergunta

Who ails tongue coddeau, aspace of dumbillsilly?10

e que simplesmente não faz sentido até que se abra mão do sentido em favor de uma leitura da materialidade fônica das palavras. Ou seja, até que se leia em voz alta e se perceba ali disfarçada a frase francesa où est ton cadeau, espèce d'imbécile? Cadê teu presente, sua besta?

O livro assim se apresenta como livro, papel, mas grita incessantemente que precisa ser lido em voz alta para que se possa chegar a algum lugar (voltaremos a isso). Mas a ideia de negar a semântica clara, aquilo que Joyce chamou de gramática lúcida, vai muito além disso, e pode ser efetivamente sintetizada numa explicação do principio básico do mecanismo verbal do Wake, que consiste numa glorificação do multilinguismo, aceitando algo entre 60 e 70 e tantas línguas diferentes (com conseqüente relativização da possibilidade de uma leitura lingüística padrão) e uma simultânea glorificação do trocadilho como principio composicional.

Com isso, Joyce atinge aqueles dois objetivos previamente mencionados com uma clareza e uma eficiência jamais atingidas previamente, ao menos não neste grau de conseqüência, num trabalho desta extensão.

Pois a semântica do Wake acaba por não ser complexificada, como nas típicas obras difíceis, em que custa ao leitor muito mais esforço o processo de compreensão. O que acontece aqui na verdade é uma relativização da validade deste mesmo processo. Ao compor seus lexemas de pedaços de palavras, sobrepostos, distorcidos, adulterados, picotados e emendados, Joyce ao mesmo tempo levava a cabo sua tendência de se descrever como um operário da "tesoura e da cola", mais que da "pena", e desferia um dos golpes mais violentos que alguns dos princípios centrais da linguagem puderam receber da literatura.

As palavras do Wake (em seu mais típico: o livro oscila entre graus diferentes de obscuridade) definitivamente não querem dizer isso ou aquilo. Suas frases, seus parágrafos, seus episódios, se aproximam muito curiosamente da definição de Copland para a música. Eles insinuam incessantemente que, sim, há ali sentido (e o fazem a partir da inclusão incessante de fragmentos reconhecíveis de semas, retirados no entanto de diversas línguas, em mais uma provocação, mais uma relativização), há ali possibilidade de leitura. Mas nenhum de nossos mecanismos usuais de leitura há de dar conta da descoberta desse sentido insinuado. E aquele mesmo mecanismo como que nos libera para um processo de atribuição

${ }^{10} \mathrm{p}, 15$. 
de sentido (que explica a centralidade do Wake para a ideia de obra aberta de Eco) que em muito pouco lembra a compreensão linguística, semântica, sintática. Normal.

Mais ainda, por esta mesma via, as palavras do Wake, se não apontam claramente para este ou aquele significado, apontando parcialmente para várias possibilidades de significado, o fazem de forma inegavelmente simultânea.

Numa tentativa de "ler" algo como riverrun, famosa minúscula primeira palavra do romance, críticos diferentes já enxergaram o francês riverain (ribeirinho), o italiano riverranno (voltarão a vir), o francês rêverons (sonhemos), além, claro, do inglês river run (um rio que corre, ou um trecho de um rio) e da possibilidade de um river ann (rio Ana, nome da protagonista), todas possibilidades, diga-se de passagem, em estreita consonância com temas e ideias da abertura do romance. E todas possibilidades simultaneamente válidas. E nenhuma plenamente realizada.

Esses significados insinuados, por se basearem em fragmentos de lexemas, e por buscarem esses fragmentos em diversas línguas, fazendo com que a mesma sequência de grafemas possa ler lida como pedaço de um signo completo francês e de outro, italiano, enquanto participa, com outras sequências truncadas, da formação de um novo lexema que se realiza, ele também, múltiplo e parcial, são necessariamente insinuações simultâneas de possibilidades não hierarquicamente elencáveis, não preferíveis, não esclarecíveis e não ordenáveis.

Por isso o $W$ ake se aproximar em muito mais do como podemos ouvir música. Por isso ele se aproximar ineditamente do ideal mallarmaico de pintar efeitos, efeitos, para todos os efeitos, indescritíveis verbalmente.

Foi preciso tocar, talvez ultrapassar as fronteiras do discurso, da língua. Mas Joyce consegue fazê-lo (e, com isso, se aproximar da música de forma inédita), sem romper as fronteiras da linguagem, pelo mero princípio de descaracterizar as línguas, e de se basear, curiosamente, em uma espécie de reflexo semântico, um hábito de leitura enquanto atribuição de sentido, para praticamente romper com a semântica clara, determinada. É dentro da linguagem e através de mecanismos estritamente lingüísticos que ele consegue fazer a linguagem se fundir com a música.

E, mais ainda, é também dentro da literatura, e através de mecanismos estritamente literários que ele o faz. Já que essa liberdade, já que essa "invenção" não aparecem no livro como veleidades criativas, virtuosismo verbal, mas como conseqüência direta daquela integração forma-conteúdo (veja: não iconização, não espelhamento, não paralelismo, efetiva e total integração). Afinal, como Joyce não cansava de repetir, em "defesa" da lógica do Wake, trata-se de um livro sobre a noite, o sonho, os sonhos, o inconsciente, e toda uma parcela de nossa existência, e inclusive de nossa inexistência, que se desenrola segundo regras e procedimentos 
que simplesmente não são redutíveis aos mecanismos e às categorias de nossa mente desperta.

Freud pôde querer explicar, glosar em termos claros a obscuridade tanto dos sonhos quanto do inconsciente. A Joyce, como romancista, cabia por outro lado tomar essas matérias como tema e, eis o desafio que ele aceita, integrá-las a sua técnica, precisamente como vinha fazendo desde suas primeiras narrativas.

O diferencial aqui, no entanto, é o fato de que agora tais temas pertencem à esfera não apenas do não-linguístico como talvez do nãoverbalizável de todo, do não-compreensível. O $W$ ake fala de forma obscura, fala de forma incompreensível, porque assim é seu tema, e só assim ele se mostra.

Daí a relativização da semântica, daí a relativização da linearidade, da biunivocidade signo-sentido, daí toda uma lógica onírica alógica, quase alinguística, quase aliterária por motivos no entanto literários, com mecanismos no entanto linguísticos, daí talvez a mais efetiva possibilidade de a literatura finalmente chegar à condição de música, aquele estado em que, para Leonard Bernstein, se pode finalmente "nomear o inominável"11.

c.

A terceira daquelas "impossibilidades" se refere a um aspecto muito singular da obra musical, que ainda pretendo desenvolver melhor em outro texto. Ela se refere à diferença do estatuto do "original" de uma peça musical e de um romance, na esteira das famosas formulações de Benjamin em $A$ obra de arte...

Pois que o fato é que o original de um romance, reproduzível, pode no entanto manter algo da "aura" de uma obra de arte singular, de uma forma muito diferente da que se pode ver em uma partitura autógrafa. Porque o manuscrito do romance se constitui em uma realização. Uma primeira manifestação. Inauguração.

Uma partitura, por outro lado, jamais será vista como a "inauguração" de uma obra, privilégio que cabe a sua primeira execução pública. A partitura, afinal, é muito menos "a obra" que um detalhado conjunto de instruções para a realização da obra, que passa a existir apenas quando executada, que tem a capacidade de existir como tal e de afetar mesmo pessoas "analfabetas" no sistema de signos em que se escreve, que mantém com aquele autógrafo uma relação, portanto, necessariamente de maior independência. Hierarquicamente superior.

E já queles primeiros poucos exemplos de "brincadeiras" sonoras do Wake, junto da constatação de que se trata de uma obra em que a

\footnotetext{
${ }^{11}$ Em "masterclass" na Universidade de Harvard, registrada em vídeo.
} 
leitura, e a leitura em vOz alta, tem um papel completamente diferente na atribuição, na criação de seu sentido, fazem com que de diversas maneiras se possa sim pensar no livro como mais próximo de uma partitura.

Ler um romance típico, por mais que teorias mais recentes tenham questionado essa posição absoluta, sempre tem um determinado grau de atividade ancilar. Ler o $W$ ake é construí-lo. Ler um romance em voz alta é definitivamente atividade marginal, um bônus. Ler o Wake em voz alta é quase sempre a única chance de se realizar qualquer coisa que se assemelhe com uma "leitura".

Ele se inaugura quando "executado".

3.

Semiassemântico, simultaneísta, incompleto ainda na página, dependente de um "intérprete" mais que de um leitor, não vejo motivos melhores para que qualquer outra obra literária possa ser considerada uma espécie de Opus 1 dessa arte que, finalmente, atinge o estatuto de música e, finalmente, consegue fazê-lo sem abrir mão do que em si há de específico, usando curiosamente o que de mais específico haja na linguagem e na literatura para negar, para ao menos subverter essas mesmas características.

Sem deixar de ser "poesia", sem abrir mão de "querer dizer" (E é muito interessante a expressão portuguesa aqui, porque Joyce efetivamente parece se basear na ideia de que, para nós, animais simbólicos, mesmo quando aquelas tésseras de palavras reunidas em mosaicos algo abstratos não significam, não mean qualquer coisa, direta e logicamente, elas ainda querem dizer. É de sua natureza essa pulsão, e é da nossa implementá-la mesmo contra os indícios mais concretos.), sem deixar de ser literatura, sem tornar-se música, mas se aproximando dessa possibilidade de uma forma até ali (e depois?) absolutamente única.

Sendo ideia(s) e palavras.

Sendo som e sentido.

Numa obra que inclui uma partitura ${ }^{12}$, original, que faz não menos que 1500 referências $^{13}$ a canções de todo tipo de repertório, mas que consegue a integração total, efetiva, de letra e música por meios muito mais sutis.

E uma obra que, muito curiosamente, pode ter relativizado por esse mesmo processo de coexistência sintética de opostos aparentemente irreconciliáveis, ainda que eternamente sequiosos um do outro, a mesma noção direta e singela de tradução. O Finnegans Wake pode ser o mais clara e inquestionavelmente intraduzível dos romances, mas isso não porque a

\footnotetext{
${ }^{12} \mathrm{p}, 44$

${ }^{13}$ Segundo levantamento a partir de dados de Slepon.
} 
transposição de sua língua em outros idiomas seria impossível, mas sim porque ela já aparece em grande medida realizada pelo original proposto.

$\mathrm{Na}$ mesma medida em que parece desnecessário musicar o Finnegans Wake, se aceitamos essa leitura que vê nele a resolução do Streben pateriano, pode parecer redundante traduzi-lo interlinguisticamente. Posso dançar segundo sua música e cantar seu verbo. Mas as sínteses que ele realiza talvez tenham superado a necessidade de transporte, transposição, de tradução. Nesta que é uma obra em que finalmente podemos ver (ouvir) As Finnesias dê música coma poesia. ${ }^{14}$

Caetano Waldrigues Galindo cwgalindo@uol.com.br

Universidade Federal do Paraná

${ }^{14} \mathrm{p}, 317$. (Tradução minha) 


\section{Referências Bibliográficas}

COPLAND, Aaron. What to listen to in music. Nova Iorque: New American Library, 1967.

ELLMANN, Richard. James Joyce. Oxford: Oxford University Press, 1983.

JOYCE, James. Finnegans Wake. Londres, Penguin, 1992.

. Poems and exiles. Londres, Penguin, 1992.

Ulysses. (GABLER, Hans Walter, ed.; MELCHIOR, Claus \& STEPPE, Wolfhard, cols.). Londres: The Bodley Head, 2001.

MALLARMÉ, Stéphane. Correspondance complete, 1862-1871, suivi de "Lettres sur la poésie, 1872-1898”. Paris: Folio, 1995.

PATER, Walter. The Renaissance: Studies in Art and Poetry. Mineola. NY: Dover, 2005.

SLEPON, Raphael, ed. The Finnegans Wake Extensible Elucidation Treasury (FWEET) Website. <http://www.fweet.org/>. Last updated: 11 September 2009. Last viewed: 20 September 2009. 